\title{
Bergenin-activated SIRT1 inhibits TNF-a-induced pro-inflammatory response via blocking NF-kB signaling pathway
}

Bei xian Zhou ( $\sim$ zbeixian@126.com )

The People's Hospital of GaoZhou https://orcid.org/0000-0002-0102-9732

\section{Bin Wu}

Guangdong Medical University

\section{Min Chen}

Guangdong Medical University

\section{Cuifen Chen}

Guangdong Medical University

\section{Yun Gao}

Guangdong Medical University

\section{Dongming Li}

Guangdong Medical University

\section{Dan Huang}

Gaungdong Medical university

\section{Ziyu Chen}

Guangdong Medical University

\section{Xuanna Zhao}

Guangdong Medical University

\section{Qiu Huang}

Guangdong Medical university

\section{Dong Wu}

Guangdong Medical university

\section{Tianwen Lai}

Guangdong Medical University

\section{Guomei Su}

Guangdong Medical University

\section{Research}

Keywords: Asthma, Bergenin, Anti-inflammatory, Sirtuin-1, NF-kB 
Posted Date: January 13th, 2020

DOI: https://doi.org/10.21203/rs.2.20671/v1

License: (c) (i) This work is licensed under a Creative Commons Attribution 4.0 International License. Read Full License 


\section{Abstract}

\section{Background}

Bergenin, a kind of polyphenol compound, has been showed to exhibit antiulcerogenic, anti-inflammatory, antitussive and burn wound healing properties, However, its therapeutic effect on TNF-a induced proinflammatory response in airway and its potential mechanisms of actions were still unclear

\section{Aim of this study}

This study aimed to investigate the anti-inflammatory effects and possible mechanism of bergenin in TNF-a-stimulated 16-HBE cells.

\section{Materials and methods}

CCK8 was used to determine the cytotoxicity. Cytokines expression were analyzed by qRT-qPCR and ELISA. Immunofluorescence, western blotting and SIRT1 activity assay were employed to investigate the possible molecular mechanism.

\section{Results}

Our results showed that bergenin treatment obviously decreased the mRNA and protein expressions of IL6 and IL-8 in TNF-a-stimulated 16-HBE cells. Bergenin blocked TNF-a-mediated the activation of NF-kB signaling and NF-kB nuclear translocation. Interestingly, RT-qPCR and western blotting revealed that bergenin did not affect the expression of sirtuin-1 (SIRT1), but significantly increased the activity of SIRT1. Furthermore, bergenin-mediated SIRT1 activation was further confirmed by the resulted that bergenin decreased acetylation levels of NF-kB-p65 and p53. The inhibitory effects of bergenin on the mRNA and protein expression levels of IL- 6 and IL-8 were reversed by addition of SIRT1 inhibitor. In addition, combination of bergenin and dexamethasone showed additive effects on the reduction of IL- 6 and IL-8.

\section{Conclusions}

These findings demonstrated that bergenin could suppress TNF-a-induced pro-inflammatory response via augmenting SIRT1 activity to block NF-kB signaling pathway, which may contribute to provide beneficial effect for the treatment of airway inflammation in asthma.

\section{Introduction}

Asthma is a chronic inflammatory disease of airway in which characterized by abnormal immuneinflammatory responses, increased mucus secretion and airway remodeling [1,2]. The clinical symptoms of this disease presented as recurrent episodes of wheezing, changeable degree of airflow obstruction, breathlessness and airway hyperresponsiveness $[3,4]$.The epidemiological statistics showed that 
prevalence of asthma was increased in last decades, which constituted great threat to human health [57]. It should point out that airway inflammation disorder elicited by various stimulus contributed to asthma progression. Clinically available medications for asthma associated with inflammation included inhaled glucocorticoids, which has been shown that asthma individual became insensitive and sideeffects $[8,9]$. Therefore, there is urgent need to develop an alternative agent for the treatment of asthma.

Tumor necrosis factor (TNF) - $a$ is a multifunctional pro-inflammatory cytokine that has been found to be secreted in various of immune cells and bronchial epithelial cells $[10,11]$. Secreted TNF-a bind to its receptors (TNF-R p55 and p75) via an autocrine or a paracrine manner, and thereby lead to NF-KBtriggered exacerbated pro-inflammatory cytokines production $[12,13]$. Accumulating evidence has indicated that TNF-a played a critical pathogenesis role in the development of asthma. Previous studies reported that elevated levels of circulating TNF-a has been found in allergen-induced asthma patients [14]. In addition, levels of TNF-a in asthmatic patients' variety of specimens, such as bronchoalveolar lavage fluid (BALF), peripheral blood monocytes, alveolar macrophages, sputum and bronchial biopsies tissues, are much higher than healthy individual [15-17]. Furthermore, it has been found that the high levels of TNF-a are positively correlated with airway hyperresponsiveness in asthmatic patients [18]. Mechanistically, airway bronchial epithelial cells with TNF-a stimulation led to upregulated intercellular adhesion molecule-1 (ICAM-1), and vascular cell adhesion molecule-1 (VCAM-1), facilitating inflammatory cells airway infiltration $[19,20]$. Besides, TNF- $a$, a key mediator in cytokine dependent inflammatory event, causes the recruitment of neutrophils and eosinophils, which led to asthma exacerbation [21]. Thus, TNFa may be attractive therapeutic target for the treatment of asthma with inflammation. However, it has been reported that severe persistent asthmatic patients with TNF-a monoclonal antibody golimumab treatment did not show significant improvements in their FEV1 and asthma exacerbations [22].

The polyphenol compound bergenin has been showed to exhibit antiulcerogenic, anti-inflammatory, antitussive and burn wound healing properties [23]. It has been found that bergenin could ameliorates LPS-induced acute lung injury in mice by the inhibition of NF-KB-mediated pro-inflammatory response [24]. In addition, bergenin reduced the expressions of pro-inflammatory IL- 6 and TNF- $\alpha$ in experimental colitis mice [23]. However, the effects and the underlying molecular mechanism of bergenin on TNF-amediated pro-inflammatory response in asthma has not yet to be revealed. Therefore, we sought to investigate the effects of bergenin on TNF-a-mediated pro-inflammatory cytokine release and associated signaling events in airway bronchial epithelial cells. Our findings would provide new insights into the mechanism of bergenin and offer an effective candidate agent for asthma treatment.

\section{Materials And Methods \\ 2.1 Cell lines}

Human bronchial epithelial cell line (16-HBE) was acquired from Guangzhou Institute of Respiratory Disease and grown at $95 \%$ humidity and $37{ }^{\circ} \mathrm{C}, 5 \% \mathrm{CO} 2$ condition. $16-\mathrm{HBE}$ cells were cultured in 
Dulbecco's Modified Eagle's Medium (DMEM; Gibco, Carlsbad, CA, USA) containing 10\% fetal bovine serum (FBS) (Gibco).

\subsection{Cell viability}

Cytotoxicity of bergenin was estimated by Cell Counting Kit-8 (CCK-8; Dojindo, Tokyo, Japan) according to the manufacturer's instructions. Briefly, 16 -HBE cells were seeded in the 96 -well plates $(5 \times 106$ cells/well) for overnight adherence. Then, different concentrations of bergenin (0-300 $\mu \mathrm{M})$ was added to cells. After $24 \mathrm{~h}$ incubation, $10 \mu \mathrm{L}$ of CCK-8 working solution was added to each well and incubated at $37^{\circ} \mathrm{C}$ for another $1 \mathrm{~h}$. The OD value of each well was measured at $450 \mathrm{~nm}$ using a microplate reader (Thermo Fisher Scientific).

\subsection{RNA extraction, RT-PCR and qPCR}

The effects of bergenin on the mRNA levels of inflammatory cytokines were analyzed by qRT-PCR. Firstly, total RNA was extracted from the 16-HBE cells using TRIzol (Takara) according to the manufacturer's protocol. Then, $1 \propto \mathrm{g}$ of total RNA was reversed transcribe into cDNA using RT First Strand Kit (Takara). qPCR was applied to quantify the interesting genes with specific primers using SYBRß Premix Ex Taq ${ }^{\text {TM }}$ II (Takara). And qPCR primer sequences were shown in Table 1. The qPCR conditions were as follows: $95^{\circ} \mathrm{C}$ for $2 \mathrm{~min}, 40 \mathrm{cycles}$ at $95^{\circ} \mathrm{C}$ for $10 \mathrm{sec}$ and then $60^{\circ} \mathrm{C}$ for $30 \mathrm{sec}$. The related expression levels of interesting genes were normalized to internal control GAPDH gene using the $2^{-\triangle \triangle \mathrm{Ct}}$ method.

Table 1

Primers Sequences for qRT-PCR

\begin{tabular}{|l|lll|}
\hline Gene & Primers & Sequence $\mathbf{( 5}^{\prime} \rightarrow \mathbf{3}^{\prime} \mathbf{)}$ \\
\hline IL-6 & Forward & CCTGAACCTTCCAAAGATGGC \\
& Reverse & TTCACCAGGCAAGTCTCCTCA \\
IL-8 & Forward & ACTGAGAGTGATTGAGAGTGGAC \\
& Reverse & AACCCTCTGCACCCAGTTTTC \\
GAPDH & Forward & TGTTGCCATCAATGACCCCTT \\
\hline & Reverse & CTCCACGACGTACTCAGCG \\
\hline
\end{tabular}

Extraction of total protein from 16-HBE cells was using RIPA buffer supplement with $1 \mathrm{mM}$ phenylmethanesulfonyl fluoride (PMSF) and protease inhibitor cocktail (1:1000 dilution; sigma-Aldrich). BCA protein assay kit (Pierce; Thermo Fisher Scientific, Inc) was used to measure the protein concentration. Equal amounts of cell lysates $(30 \mu \mathrm{g})$ were separated by $10 \%$ SDS polyacrylamide gel electrophoresis and transferred onto nitrocellulose membrane (Amersham, GE Healthcare Europe GmbH, Milano, Italy). After blocking in $5 \%$ non-fat milk, membranes were incubated with specific primary 
antibodies at $4{ }^{\circ} \mathrm{C}$ overnight. Primary antibodies purchased from Cell Signaling Technology were as following: phosphorylated NF-KB p65, total NF-KB p65, IKB-a, acetly-p53, acetly-p65, GAPDH. membranes were washed with 1 . TBS/Tween -20 buffer $(0.1 \%, v / v)$ for three times, and then incubated with horseradish peroxidase-conjugated secondary antibodies at room temperature for $1 \mathrm{~h}$. Enhanced chemiluminescence reaction kit (ECL, Millipore, Billerica, MA, USA) were used to visualize protein bands. ImageJ software (version 1.43) was used to quantified the intensity of protein bands.

\subsection{Enzyme-linked immunosorbent assay (ELISA)}

TNF-a stimulated 16-HBE cells were treated with indicated concentration of bergenin (0-200 $\mu \mathrm{M})$. After $24 \mathrm{~h}$ incubation, culture supernatants were harvested and centrifuged at $10,000 \times \mathrm{g}$ for $15 \mathrm{~min}$. Then, supernatants were stored and frozen at $-80^{\circ} \mathrm{C}$. The levels of IL-6, IL-8 in the culture supernatants were analyzed using a Human ELISA Kit (Multisciences, Biotech Co., Ltd, Norman, OK) according to the manufacturer's protocols.

\subsection{Immunofluorescence staining}

16-HBE cells were seeded on glass coverslips inside a 48-well plate and stimulated with TNF-a $(20 \mathrm{ng} / \mathrm{ml})$ in the absence or presence of bergenin (0-200 $\mu \mathrm{M})$. After $24 \mathrm{~h}$, cells were with PBS for three times and fixing with $4 \%$ paraformaldehyde for $15 \mathrm{~min}$ at room temperature. Then, cells were permeabilized with $0.1 \%$ Triton X-100 in PBS for 10 min, and rinsed again with PBS for three times. After blocking with $5 \%$ BSA (in PBS) for 30 min, cells were incubated with primary antibody against NF-KB p65 for overnight incubation at $4{ }^{\circ} \mathrm{C}$. Next, cells were incubated with FITC-linked anti-rabbit (green, 1:100; Beyotime, Shanghai, China) secondary antibody, and 4',6-diamino-2- phenylindole (DAPI, Beyotime biotechnology, China) was utilized to stained the cells nuclei. The fluorescent signals were detected by a laser scanning confocal microscope (Olympus, Tokyo, Japan).

\subsection{SIRT1 activity assay}

In order to measure SIRT1 deacetylase activity, the extraction of nuclear proteins was performed. SIRT1 Deacetylase Activity Assay Kit (Genmed Scientifics Inc., Arlington, MA, USA) was utilized to measured SIRT1 deacetylase activity according to the manufacturer's instructions. The optical densities (OD) of each well at $405 \mathrm{~nm}$ was recorded on a microplate reader (Thermo Fisher Scientific).

\subsection{Statistic analysis}

Data are expressed as the mean \pm SEM. SPSS v. 21.0 software was used for data analyses. Statistical significance between two groups was determined by Student's t-test. P-value less than 0.05 was considered a significant difference.

\section{Results}

\subsection{Cytotoxicity of bergenin}


In order to choose appropriate concentration for the present study, we first set out to determine the cytotoxicity of bergenin on 16-HBE cells. A series concentration of bergenin ranges between $0-300 \mu \mathrm{M}$ were added to $16-\mathrm{HBE}$ cells for $24 \mathrm{~h}$ incubation. The CCK-8 results indicated that the cell viability of $16-$ HBE cells was not affected by these concentrations of bergenin (Fig. 1B). Therefore, we chose maximum concentration of bergenin was $200 \mu \mathrm{M}$ for the further experiments.

\subsection{Bergenin inhibited TNF-a-stimulated expression of pro- inflammatory cytokines in 16-HBE cells}

Accumulated evidences indicated that TNF-a-triggered abnormal pro-inflammatory response played a critical role in the pathogenesis of asthma [25]. Especially, pro-inflammatory cytokines including IL-6 and IL-8 have been shown to contribute to asthma exacerbation. Therefore, we investigated whether bergenin affected TNF-a-induced expression levels of IL-6 and IL-8 in 16-HBE cells. As shown in Figs. 2A, 2B, TNF-a stimulation significantly increased mRNA levels of IL-6 and IL-8 in bergenin-untreated cells. As expected, bergenin treatment significantly reduced the mRNA levels of IL-6, IL-8 in a dose-dependent manner as compared to the untreated group. Consistently, as shown in Figs. 2C, 2D, protein levels of IL-6 and IL-8 in the culture supernatant of TNF-a-stimulated cells was reduced in 16-HBE cells with treatment of bergenin. Therefore, these results demonstrated that bergenin has the capacity to decrease expression of IL-6 and IL-8 in TNF-a-stimulated 16-HBE cells.

\subsection{Bergenin inhibited TNF-a-mediated activation of NF-KB signaling}

NF-KB signaling is well-known for TNF-a-initiated pro-inflammatory cytokines expression [26].Given the inhibition of TNF-a-induced expression of IL- 6 and IL-8 by bergenin, we speculated that bergenin might suppress TNF-a-mediated activation of NF-KB to exert inhibitory effects on the expression of IL- 6 and IL-8. As a hallmark of NF-KB activation, degradation of IkBa was clearly suppressed by bergenin treatment (Fig. 3A). Meanwhile, in the same sample TNF-a-induced phosphorylation of p65 NF-kB was clearly inhibited by bergenin treatment (Fig. 3A). To further confirm the inhibition of NF-kB activation by bergenin, immunofluorescence was employed to investigate the effect of bergenin on NF-kB nuclear translocation. The results showed that bergenin treatment significantly blocked TNF-a-induced p65 NF-KB nuclear translocation (Fig. 3C). Therefore, these results so far indicated that the inhibitory effects of TNFa-induced expression of IL- 6 and IL-8 by bergenin might be associated with its NF-KB-inhibiting activity.

\subsection{Bergenin acted as SIRT1 agonist in response to TNF-a stimulation.}

Previous results reported that SIRT1 as a deacetylase is responsible for p65 NF-KB acetylation, and subsequently decreased NF-KB nuclear translocation [27]. As the above results revealed that bergenin inactivated NF-KB in response to TNF-a stimulation, it was necessary to clarify whether the inhibitory 
effects on NF-KB activation by bergenin was associated with its biological property by modulation of SIRT1. Firstly, we employed qRT-PCR and immunoblotting to investigate the effects of bergenin on the expression of SIRT1. Interestingly, bergenin treatment did not affect the mRNA and protein expression levels of SIRT1 (Fig. 4A and 4B). While, TNF-a-mediated reduction of SIRT1 activity was dose-dependently increased by bergenin treatment (Fig. 4C). Simultaneously, the activation of SIRT1 activity by bergenin was further confirmed by the results of decreased acetylation level of p53 (Fig. 4D). Moreover, the acetylation of p $65 \mathrm{NF}-\mathrm{kB}$ was also significantly decreased by bergenin treatment (Fig. 4E). So far, we can suppose that the inhibition effect of NF-KB by bergenin treatment might be due to its SIRT1-activated property. Therefore, we investigated the expression of pro-inflammatory cytokines to confirm this speculation in begernin-treated cells with or without SIRT1 inhibitor salermide treatment. As shown in Fig. $5 \mathrm{G}$ and $5 \mathrm{H}$, inhibition effects of begernin on TNF-a-induced IL- 6 and IL-8 were reversed by addition of salermide. Taken together, these results suggested that begernin treatment has capacity to increase SIRT1 activity, and thereby contribute to suppress NF-KB-mediated expression of pro-inflammatory cytokines in response to TNF-a stimulation.

\subsection{Combination of dexamethasone and bergenin treatment effectively reduced TNF-a-induced pro-inflammatory cytokines expression}

Inhaling glucocorticoids such as dexamethasone are widely applied to in treatment of asthmatic patient with airway inflammation [28]. However, a growing body of evidence indicated that many patients with asthma gradually became insensitive to glucocorticoids treatment. The above results suggested that bergenin could decrease TNF-a-induced pro-inflammatory cytokines. Therefore, we wondered whether bergenin has the potential to increase the glucocorticoids sensitiveness. As expected, we found that combination of bergenin and dexamethasone treatment caused an additive effect on reduction of IL- 6 and IL-8 in TNF-a-stimulated 16-HBE cells (Fig. 5A and 5B). These results indicated that bergenin may serve as an adjunct to pharmacotherapy for glucocorticoid-insensitive asthma.

\section{Discussion}

In the present study, we investigated the anti-inflammatory effects of bergenin using TNF-a-stimulated human bronchial epithelial cells model. Our results showed that bergenin significantly decreased TNF-amediated production of IL-6 and IL-8 at mRNA and protein in 16-HBE cells, which was found to as a result of its NF-KB inhibition property. Further study demonstrated that the NF-KB inhibition property of bergenin was associated with increased SIRT1 activity. Moreover, the combination of bergenin and dexamethasone treatment could exert additive reduction effects on TNF-a-mediated expression of IL-6 and IL-8.

Bronchial epithelium cells served as a barrier to maintain lung homeostasis and protected against external harmful stimulus. However, persistent damages to the bronchial epithelium driven dysregulation 
of pro-inflammatory response, which was supposed to be involved in the context of airway remodeling and progression to asthma.

Diverse research suggested that the early immune response in the airway is regulated mainly by the proinflammatory cytokine TNF-a $[25,29]$. Both of abnormal inflammation and airway remodeling are key histopathologic features in asthma[30]. Upon TNF-a stimulation, the neutrophils and eosinophils airway recruitment, and the increased release of cytokines have been demonstrated to contribute to early onset asthma and asthma exacerbation [21, 31]. In addition, TNF- $a$ could upregulate the expression of transforming growth factor (TGF) $-\beta 1$, which has been shown to be implicated in airway remodeling in severe asthma [32]. These evidences all indicated that the pathogenesis role of TNF-a during the progression of asthma. For these reasons, TNF-a has been suggested as an important target for asthma control. Therefore, in this study, we employed 16-HBE cells with TNF-a stimulation to investigate whether bergenin could exert inhibitory effects on TNF-a-induced pro-inflammatory response.

Our study showed that bergenin has an inhibitory effect on TNF-a-mediated elevation of IL-6 and IL-8 in $16-\mathrm{HBE}$ cells. Accumulated evidences have provided a correlation between these pro-inflammatory mediators and asthma in both mouse models of allergic asthma and patients with asthma. The amounts of IL- 6 has been found to be increased in the sputum and BAL fluid of patients with asthma [33, 34]. IL- 6 levels significantly correlated with disease severity and lower forced expiratory volume in 1 second (FEV1) in children and adults with asthma $[35,36]$. Blockade of IL-6 attenuated airway recruitment of eosinophil and neutrophil in allergen-challenged mice [37]. In addition, IL-8, a powerful chemoattractant of neutrophil, has also been thought to play an indispensable role in initiating and/or exacerbating of asthma[38]. Kinetics of IL-8 showed that level of IL-8 was significantly increased in acute exacerbation of asthma, but was decreased at resolution [39]. It is postulated that the increased IL-8 was responsible for virus-driven asthma exacerbations and correlated with more neutrophils in the sputum of asthma patients [40]. IL-8-recruited neutrophil was believed to lead to development of severe clinical forms of neutrophilic asthma, which was intractable for asthma treatment due to frequent steroid resistance [41]. Thus, IL-8 could be developed as attractive target for neutrophilic asthma. Based on these evidences, down-regulation of IL-6 and IL-8 by bergenin treatment may sever as effective strategy for asthma management

The transcription factor NF-kB was well-known for pro-inflammatory cytokines initiation, and has been demonstrated to be closely associated with the development of asthma [42]. Aberrant activation of NF-KB caused the proliferation of airway smooth muscle cells, resulting in airway narrowing and hyperresponsiveness in asthmatic [43]. Increased NF-KB nuclear translocation has been observed in the airway recruited inflammatory cells of asthmatics [44]. Besides, NF-KB subunit (including p50 or c-Rel) deficiency in mice abrogated the development of allergic asthma, which directly supported that functional role of NF-KB in the pathogenesis of allergic airways disease $[45,46]$. Upon allergens airway exposure, released of many pro-inflammatory mediators including IL-6 and IL-8 were regulated, at least in part, by NF-KB $[47,48]$. The results of the present study demonstrated that bergenin suppressed degradation of 
IkBa, phosphorylation of $\mathrm{p} 65 \mathrm{NF}-\mathrm{kB}$ and NF-kB nuclear translocation. Therefore, we can suppose that the decreased of IL- 6 and IL-8 secretion by bergenin was due to inhibition of NF-KB activation.

Interestingly, our results showed that expression levels of SIRT1 was not affected by bergenin, but the decreased SIRT1 activity mediated by TNF-a stimulation was significantly reversed by bergenin. SIRT1, belonging to a member of NAD+-dependent class III histone/protein deacetylases (HDACs), has been reported to be implicated in deacetylate a variety of substrates, and thus affected a series of cellular pathophysiology process[49]. Research showed that the suppression of SIRT1 activity has been shown to be involved in promoting the progression of asthma [50]. This implied us that increased the SIRT1 activity by novel agents might appears to be a very promising strategy for the treatment of severe uncontrolled asthma. In addition, previous study indicated that activated SIRT1 could attenuate NF-kB-driven inflammatory response upon LPS or TNF-a stimulation [27, 51]. Our above-mentioned results showed that bergenin inhibited NF-KB activation. Therefore, we investigated the effect of increased SIRT1 activity by bergenin on the post-translational modification of NF-KB-p65 in TNF-a-stimulated 16-HBE cells. As expected, acetylation status of NF-KB-p65 was decreased by bergenin treatment. Moreover, the SIRT1 inhibitor salermide reversed the anti-inflammatory effects of bergenin in TNF-a-stimulated 16-HBE cells. Therefore, we can suppose that the increased SIRT1 activity by bergenin could deacetylate NF-KB-p65; in turn the inhibition of NF-KB reduced TNF-a-induced production of IL-6 and IL-8.

Inhaled or oral glucocorticoids has been extensively applied to control excess airway inflammation of asthmatic in clinic. However, it has been shown that increased number of patients with asthma gradually fail to respond to glucocorticoids. The molecular mechanism underlying of glucocorticoid resistance or insensitivity was due to excessive activation of MAPK and NF-KB signaling pathway [52]. Furthermore, increased NF-KB activation is closely correlated with the severity of asthma [53]. Therefore, it was proposed that inactivation of NF-KB could provide beneficial effects in the treatment of asthma. In accordance with this, our data indicated that combination of bergenin and dexamethasone exerted additive effects on TNF-a-mediated production of IL- 6 and IL-8. Thus, we can suppose that the additive anti-inflammatory effect may be a result of the inhibition property on NF-KB by bergenin. Therefore, we believed that bergenin can contribute as an adjunct to the treatment of glucocorticoid resistance in asthma.

\section{Conclusions}

In summary, bergenin can significantly attenuate TNF-a-induced pro-inflammatory response in 16-HBE cells. The underlying mechanism of its anti-inflammatory property was associated with increased SIRT activity, and thereby contribute to suppression of NF-KB-p65 acetylation and concomitant inhibition of production of IL- 6 and IL- 8 . Therefore, bergenin might be contribute to therapeutic potential for the prevention and management of airway inflammation in asthma.

\section{Abbreviations}


BCA Bicinchoninic acid

GAPDH Glyceraldehyde 3-phosphate dehydrogenase

TNF-a Tissue Necrosis Factor-alpha

IL Interleukin

NF-kB Nuclear factor kappa B

SIRT1 Sirtuin-1

qRT-PCR Quantitative reverse transcription PCR

ELISA Enzyme-linked immunosorbent assay

BALF Bronchoalveolar lavage fluid

ICAM-1 Intercellular adhesion molecule-1

VCAM-1 Vascular cell adhesion molecule-1

FBS Fetal bovine serum

CCK-8 Cell Counting Kit-8

FEV1 Expiratory volume in 1 second

\section{Declarations}

\section{Acknowledgments}

We sincerely thank members of our laboratory for their technical and theoretical help.

\section{Authors' contributions}

Conceived and designed the experiments: Bin Wu and Beixian Zhou. Performed the experiments: Min Chen, Cuifen Chen, Yun Gao, Ziyu Chen, Xuanna Zhao, Qiu Huang. Analyzed the data: Dongming Li, Dan Huang, Dong Wu and Tianwen Lai. Wrote and revised the paper: Bin Wu, Beixian Zhou and Cuifen Chen.

\section{Funding}

This work was supported by the National Natural Science Foundation of China (Grant No.81670025)

Availability of data and materials

Not applicable 


\section{Ethics approval and consent to participate}

Not applicable

\section{Consent for publication}

Not applicable

\section{Conflict of interests}

All authors declare that they have no competing interests.

\section{Publisher's Note}

Springer Nature remains neutral with regard to jurisdictional claims in published maps and institutional affiliations.

\section{Contributor Information}

Min Chen, Email: 948299690@qq.com

Cuifen Chen, Email: 394629706@qq.com

Yun Gao, Email: 523088828@qq.com

Dongming Li, Email: 1335887835@qq.com

Dan Huang, Email: 287538250@qq.com

Ziyu Chen, Email: 1621687187@qq.com

Xuanna Zhao, Email: 1820180139@qq.com

Qiu Huang, Email: 1009007246@qq.com

Dong Wu, Email: Wudong98@126.com

Tianwen Lai, Email: Laitianwen2011@163.com

Guomei Su, Email: 1451142004@qq.com

Beixian Zhou, Email: zbeixian@126.com

Bin Wu, Phone: 0759-2386792, Email: Wubin621011@126.com

\section{References}


1. Busse WW, Lemanske RF, Jr.: Asthma. N Engl J Med 2001, 344:350-362.

2. Ito K, Herbert C, Siegle JS, Vuppusetty C, Hansbro N, Thomas PS, Foster PS, Barnes PJ, Kumar RK: Steroid-resistant neutrophilic inflammation in a mouse model of an acute exacerbation of asthma. Am J Respir Cell Mol Biol 2008, 39:543-550.

3. Braman SS: The global burden of asthma. Chest 2006, 130:4s-12s.

4. Mims JW: Asthma: definitions and pathophysiology. Int Forum Allergy Rhinol 2015, 5 Suppl 1:S2-6.

5. Nunes C, Pereira AM, Morais-Almeida M: Asthma costs and social impact. Asthma Res Pract 2017, $3: 1$.

6. Bahadori K, Doyle-Waters MM, Marra C, Lynd L, Alasaly K, Swiston J, FitzGerald JM: Economic burden of asthma: a systematic review. BMC Pulm Med 2009, 9:24.

7. Masoli M, Fabian D, Holt S, Beasley R: The global burden of asthma: executive summary of the GINA Dissemination Committee report. Allergy 2004, 59:469-478.

8. Jang AS: Steroid response in refractory asthmatics. Korean J Intern Med 2012, 27:143-148.

9. Volmer T, Effenberger T, Trautner C, Buhl R: Consequences of long-term oral corticosteroid therapy and its side-effects in severe asthma in adults: a focused review of the impact data in the literature. Eur Respir J 2018, 52.

10. Rahman MM, McFadden G: Modulation of tumor necrosis factor by microbial pathogens. PLoS Pathog 2006, 2:e4.

11. Aggarwal BB: Signalling pathways of the TNF superfamily: a double-edged sword. Nat Rev Immunol 2003, 3:745-756.

12. Bigda J, Holtmann H: TNF receptors-how they function and interact. Arch Immunol Ther Exp (Warsz) 1997, 45:263-270.

13. Parameswaran N, Patial S: Tumor necrosis factor-alpha signaling in macrophages. Crit Rev Eukaryot Gene Expr 2010, 20:87-103.

14. Babu SK, Puddicombe SM, Arshad HH, Wilson SJ, Ward J, Gozzard N, Higgs G, Holgate ST, Davies DE: Tumor necrosis factor alpha (TNF-alpha) autoregulates its expression and induces adhesion molecule expression in asthma. Clin Immunol 2011, 140:18-25.

15. Gosset P, Tsicopoulos A, Wallaert B, Vannimenus C, Joseph M, Tonnel AB, Capron A: Increased secretion of tumor necrosis factor alpha and interleukin- 6 by alveolar macrophages consecutive to the development of the late asthmatic reaction. J Allergy Clin Immunol 1991, 88:561-571.

16. Gosset P, Tsicopoulos A, Wallaert B, Joseph M, Capron A, Tonnel AB: Tumor necrosis factor alpha and interleukin-6 production by human mononuclear phagocytes from allergic asthmatics after IgEdependent stimulation. Am Rev Respir Dis 1992, 146:768-774.

17. Keatings VM, O'Connor BJ, Wright LG, Huston DP, Corrigan CJ, Barnes PJ: Late response to allergen is associated with increased concentrations of tumor necrosis factor-alpha and IL-5 in induced sputum. J Allergy Clin Immunol 1997, 99:693-698. 
18. Grzelewska-Rzymowska I, Pietrzkowicz M: [Role of tumor necrosis factor-alpha in allergic inflammation and airway hyperresponsiveness]. Pol Merkur Lekarski 2004, 16:173-178.

19. Pober JS: Endothelial activation: intracellular signaling pathways. Arthritis Res 2002, 4 Suppl 3:S109116.

20. Montefort S, Holgate ST: Adhesion molecules and their role in inflammation. Respir Med 1991, 85:9199.

21. Thomas PS: Tumour necrosis factor-alpha: the role of this multifunctional cytokine in asthma. Immunol Cell Biol 2001, 79:132-140.

22. Wenzel SE, Barnes PJ, Bleecker ER, Bousquet J, Busse W, Dahlen SE, Holgate ST, Meyers DA, Rabe KF, Antczak A, et al: A randomized, double-blind, placebo-controlled study of tumor necrosis factor-alpha blockade in severe persistent asthma. Am J Respir Crit Care Med 2009, 179:549-558.

23. Wang K, Li YF, Lv Q, Li XM, Dai Y, Wei ZF: Bergenin, Acting as an Agonist of PPARgamma, Ameliorates Experimental Colitis in Mice through Improving Expression of SIRT1, and Therefore Inhibiting NF-kappaB-Mediated Macrophage Activation. Front Pharmacol 2017, 8:981.

24. Yang S, Yu Z, Wang L, Yuan T, Wang X, Zhang X, Wang J, Lv Y, Du G: The natural product bergenin ameliorates lipopolysaccharide-induced acute lung injury by inhibiting NF-kappaB activition. $J$ Ethnopharmacol 2017, 200:147-155.

25. Zhang L, Zhang X, Zheng J, Liu Y, Wang J, Wang G, Zhang HP, Kang Y, Peng ZG, Ji YL, et al: Depressive symptom-associated IL-1beta and TNF-alpha release correlates with impaired bronchodilator response and neutrophilic airway inflammation in asthma. Clin Exp Allergy 2019, 49:770-780.

26. Pozniak PD, White MK, Khalili K: TNF-alpha/NF-kappaB signaling in the CNS: possible connection to EPHB2. J Neuroimmune Pharmacol 2014, 9:133-141.

27. Yang H, Zhang W, Pan H, Feldser HG, Lainez E, Miller C, Leung S, Zhong Z, Zhao H, Sweitzer S, et al: SIRT1 activators suppress inflammatory responses through promotion of p65 deacetylation and inhibition of NF-kappaB activity. PLoS One 2012, 7:e46364.

28. Alangari AA: Corticosteroids in the treatment of acute asthma. Ann Thorac Med 2014, 9:187-192.

29. Lee HS, Park HW, Song WJ, Jeon EY, Bang B, Shim EJ, Moon HG, Kim YK, Kang HR, Min KU, Cho SH: TNF-alpha enhance Th2 and Th17 immune responses regulating by IL23 during sensitization in asthma model. Cytokine 2016, 79:23-30.

30. Kudo M, Ishigatsubo Y, Aoki I: Pathology of asthma. Front Microbio/ 2013, 4:263.

31. Lukacs NW, Strieter RM, Chensue SW, Widmer M, Kunkel SL: TNF-alpha mediates recruitment of neutrophils and eosinophils during airway inflammation. $J$ Immuno/ 1995, 154:5411-5417.

32. Sullivan DE, Ferris M, Pociask D, Brody AR: Tumor necrosis factor-alpha induces transforming growth factor-beta1 expression in lung fibroblasts through the extracellular signal-regulated kinase pathway. Am J Respir Cell Mol Biol 2005, 32:342-349. 
33. Konno S, Gonokami Y, Kurokawa M, Kawazu K, Asano K, Okamoto K, Adachi M: Cytokine concentrations in sputum of asthmatic patients. Int Arch Allergy Immunol 1996, 109:73-78.

34. Mattoli S, Mattoso VL, Soloperto M, Allegra L, Fasoli A: Cellular and biochemical characteristics of bronchoalveolar lavage fluid in symptomatic nonallergic asthma. J Allergy Clin Immunol 1991, 87:794-802.

35. Cui AH, Zhao J, Liu SX, Hao YS: Associations of IL-4, IL-6, and IL-12 levels in peripheral blood with lung function, cellular immune function, and quality of life in children with moderate-to-severe asthma. Medicine (Baltimore) 2017, 96:e6265.

36. Peters MC, McGrath KW, Hawkins GA, Hastie AT, Levy BD, Israel E, Phillips BR, Mauger DT, Comhair SA, Erzurum SC, et al: Plasma interleukin-6 concentrations, metabolic dysfunction, and asthma severity: a cross-sectional analysis of two cohorts. Lancet Respir Med 2016, 4:574-584.

37. Chu DK, Al-Garawi A, Llop-Guevara A, Pillai RA, Radford K, Shen P, Walker TD, Goncharova S, Calhoun WJ, Nair P, Jordana M: Therapeutic potential of anti-IL-6 therapies for granulocytic airway inflammation in asthma. Allergy Asthma Clin Immunol 2015, 11:14.

38. Zhang J, Bai C: Elevated Serum Interleukin-8 Level as a Preferable Biomarker for Identifying Uncontrolled Asthma and Glucocorticosteroid Responsiveness. Tanaffos 2017, 16:260-269.

39. Norzila MZ, Fakes K, Henry RL, Simpson J, Gibson PG: Interleukin-8 secretion and neutrophil recruitment accompanies induced sputum eosinophil activation in children with acute asthma. Am J Respir Crit Care Med 2000, 161:769-774.

40. Teran LM, Johnston SL, Schroder JM, Church MK, Holgate ST: Role of nasal interleukin-8 in neutrophil recruitment and activation in children with virus-induced asthma. Am J Respir Crit Care Med 1997, 155:1362-1366.

41. Ray A, Kolls JK: Neutrophilic Inflammation in Asthma and Association with Disease Severity. Trends Immunol 2017, 38:942-954.

42. Kumar A, Takada Y, Boriek AM, Aggarwal BB: Nuclear factor-kappaB: its role in health and disease. $J$ Mol Med (Berl) 2004, 82:434-448.

43. Brar SS, Kennedy TP, Sturrock AB, Huecksteadt TP, Quinn MT, Murphy TM, Chitano P, Hoidal JR: NADPH oxidase promotes NF-kappaB activation and proliferation in human airway smooth muscle. Am J Physiol Lung Cell Mol Physiol 2002, 282:L782-795.

44. Hart LA, Krishnan VL, Adcock IM, Barnes PJ, Chung KF: Activation and localization of transcription factor, nuclear factor-kappaB, in asthma. Am J Respir Crit Care Med 1998, 158:1585-1592.

45. Donovan CE, Mark DA, He HZ, Liou HC, Kobzik L, Wang Y, De Sanctis GT, Perkins DL, Finn PW: NFkappa B/Rel transcription factors: c-Rel promotes airway hyperresponsiveness and allergic pulmonary inflammation. J Immunol 1999, 163:6827-6833.

46. Yang L, Cohn L, Zhang DH, Homer R, Ray A, Ray P: Essential role of nuclear factor kappaB in the induction of eosinophilia in allergic airway inflammation. $J$ Exp Med 1998, 188:1739-1750.

47. Coward WR, Sagara H, Wilson SJ, Holgate ST, Church MK: Allergen activates peripheral blood eosinophil nuclear factor-kappaB to generate granulocyte macrophage-colony stimulating factor, 
tumour necrosis factor-alpha and interleukin-8. Clin Exp Allergy 2004, 34:1071-1078.

48. Cheng DS, Han W, Chen SM, Sherrill TP, Chont M, Park GY, Sheller JR, Polosukhin VV, Christman JW, Yull FE, Blackwell TS: Airway epithelium controls lung inflammation and injury through the NF-kappa B pathway. J Immunol 2007, 178:6504-6513.

49. Yamamoto H, Schoonjans K, Auwerx J: Sirtuin functions in health and disease. Mol Endocrino/ 2007, 21:1745-1755.

50. Tang L, Chen Q, Meng Z, Sun L, Zhu L, Liu J, Hu J, Ni Z, Wang X: Suppression of Sirtuin-1 Increases IL-6 Expression by Activation of the Akt Pathway During Allergic Asthma. Cell Physiol Biochem 2017, 43:1950-1960.

51. Shen Z, Ajmo JM, Rogers CQ, Liang X, Le L, Murr MM, Peng Y, You M: Role of SIRT1 in regulation of LPS- or two ethanol metabolites-induced TNF-alpha production in cultured macrophage cell lines. Am J Physiol Gastrointest Liver Physiol 2009, 296:G1047-1053.

52. Matsumura Y: Heterogeneity of glucocorticoid resistance in patients with bronchial asthma. Int $J$ Biomed Sci 2010, 6:158-166.

53. Abdulamir AS, Kadhim HS, Hafidh RR, Ali MA, Faik I, Abubakar F, Abbas KA: Severity of asthma: the role of CD25+, CD30+, NF-kappaB, and apoptotic markers. J Investig Allergol Clin Immunol 2009, 19:218-224.

\section{Figures}

$\mathbf{A}$<smiles>COc1c(O)cc2c(c1O)[C@]1([C@H](C)O)O[C@H](CO)[C@@H](O)[C@H](O)[C@H]1OC2=O</smiles>

B

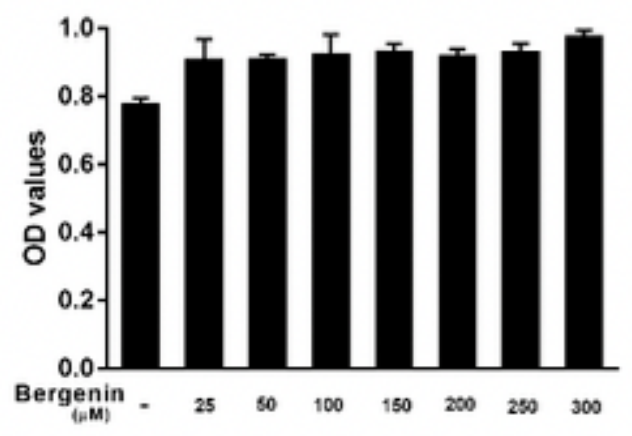

Figure 1

Cellular toxicity of bergenin on 16-HBE cells. (A)The chemical structure of bergenin. (B) 16-HBE cells were incubated with indicated with bergenin $(0-300 \mu \mathrm{M})$ for $24 \mathrm{~h}$. Cell viability was detected by CCK-8. Data were presented as means \pm SEM of three independent experiments. 

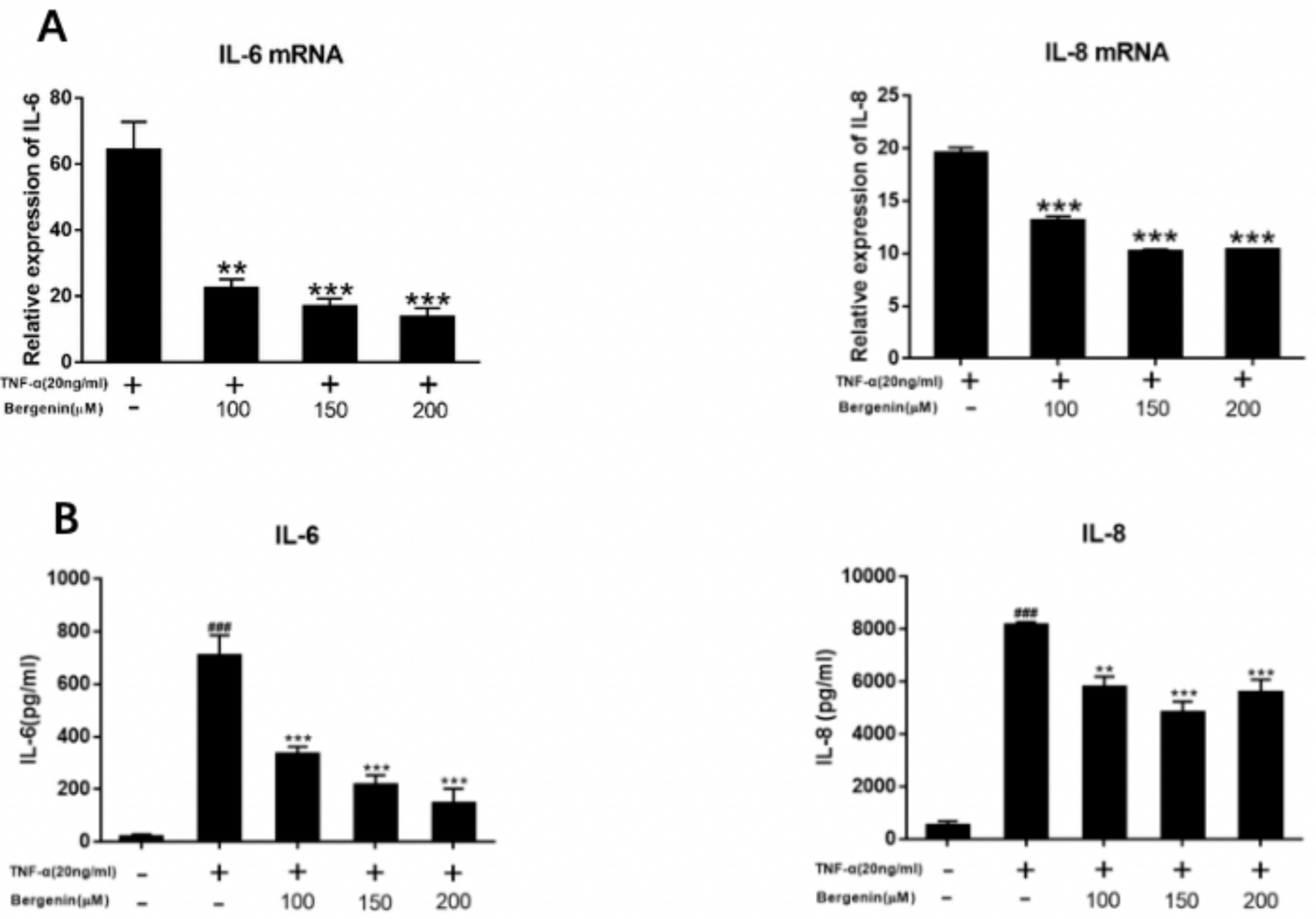

Figure 2

Effects of bergenin on TNF-囚-induced expression of pro-inflammatory cytokines in 16-HBE cells. (A) 16-

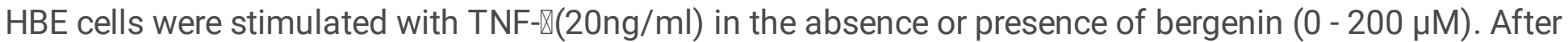
$24 \mathrm{~h}, \mathrm{qRT}-\mathrm{PCR}$ was carried out to measure mRNA expression levels of IL-6 and IL-8. (B) The expression levels of IL-6 and IL-8 in the culture supernatant in TNF-囚-treated 16-HBE cells with or without bergenin ( 0 $200 \mu \mathrm{M})$ treatment were measured by ELISA. Data were presented as means \pm SEM of three independent experiments. \#\#\#P $<0.001$ compared to untreated cells; $* * \mathrm{P}<0.01 ; * * * \mathrm{P}<0.001$ compared to TNF-囚treated alone. 


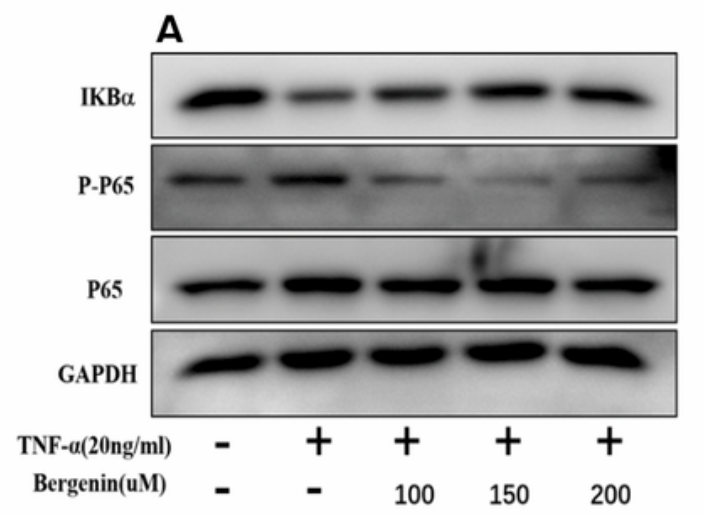

B

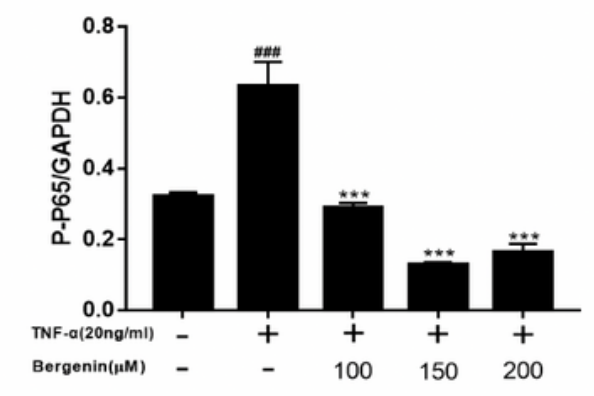

\section{B}

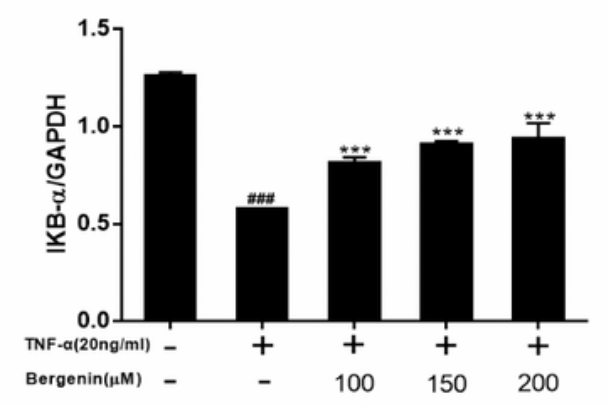

B

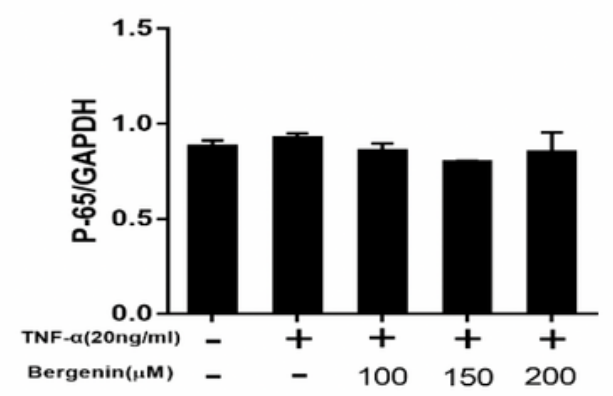

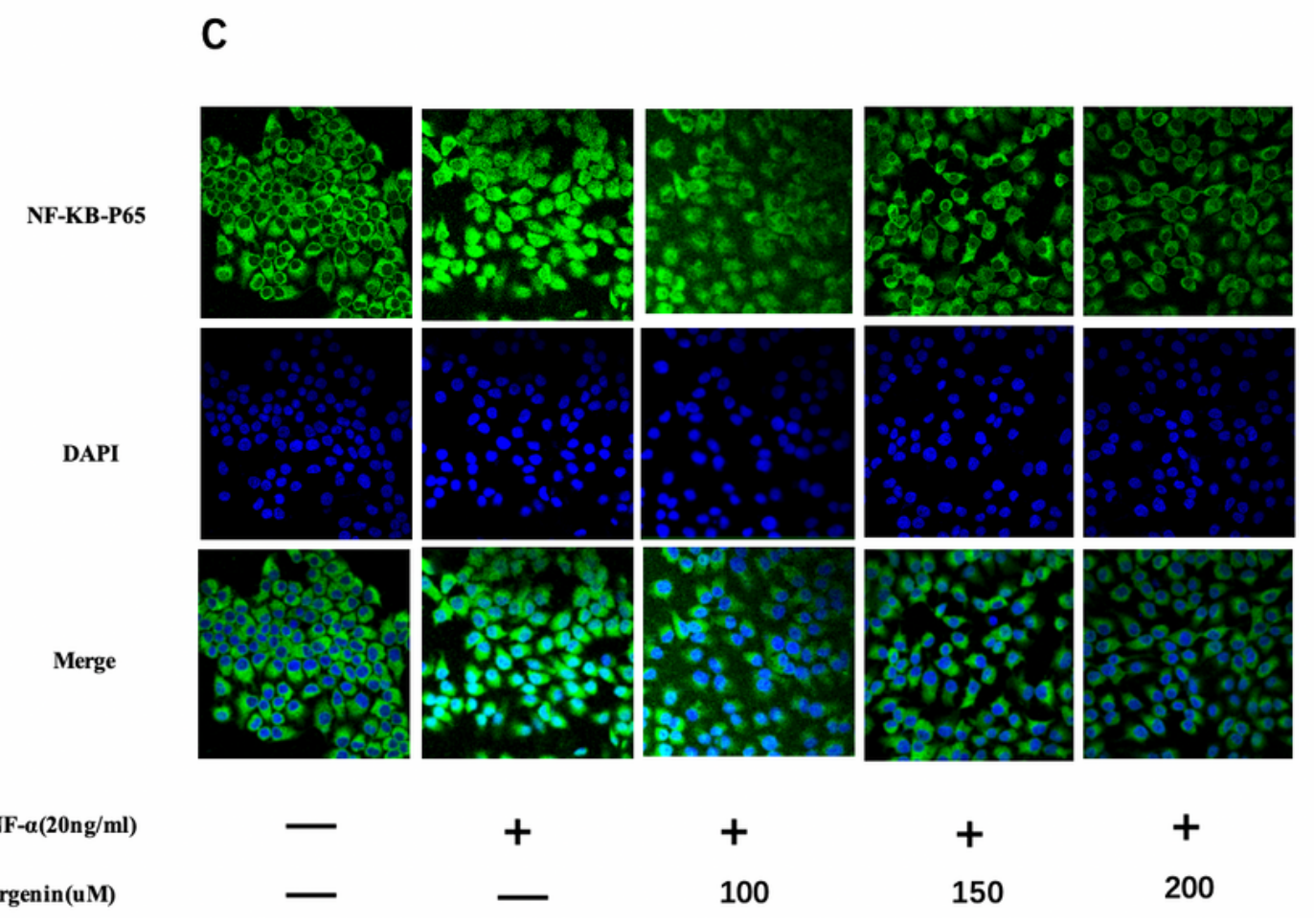

\section{Figure 3}

Effect of bergenin on the activation of NF- $\mathrm{BB}$ signaling pathway in TNF-X-stimulated 16-HBE cells. (A) 16HBE cells were stimulated with TNF- $\triangle(20 \mathrm{ng} / \mathrm{ml})$ in the absence or presence of bergenin $(0-200 \mu \mathrm{M})$. After $24 \mathrm{~h}$, cells were harvested and levels of IKBa and phosphorylated p65 NF-KB were determined by western blotting. GAPDH was used as internal control. (B) Protein band intensities of IKBa and P-P65 NF-nB in (A) were measured by ImageJ software. Data were presented as means \pm SEM of three independent 
experiments. \#\#\#P $<0.001$ compared to untreated cells; $* * * \mathrm{P}<0.001$ compared to TNF-囚-treated alone. (C) Immunofluorescence confocal microscopy was used to monitor the TNF-a-stimulated p65 NF-kB (Green) nuclear translocation in the absence or presence of bergenin $(0-200 \mu \mathrm{M})$ treatment. Nuclei were counterstained with DAPI (Blue).
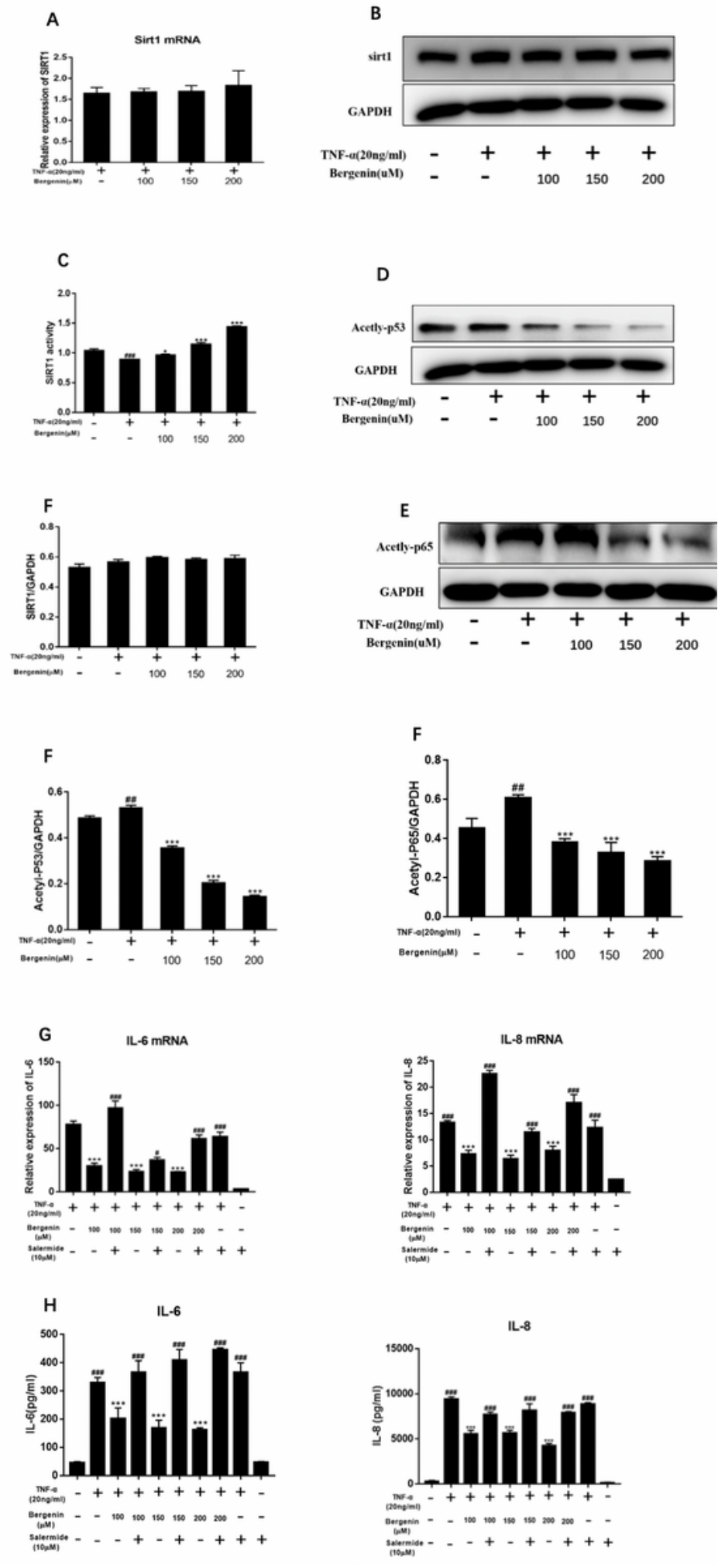

Figure 4 
Effects of SIRT1 inhibitor salermide on bergenin-inhibited expression of pro-inflammatory cytokines in TNF-囚-stimulated 16-HBE cells. (A-B) 16-HBE cells were stimulated with TNF- $\mathbb{~}(20 \mathrm{ng} / \mathrm{ml})$ and incubated with bergenin $(0-200 \mu \mathrm{M})$ for $24 \mathrm{~h}$. mRNA and protein levels of SIRT1 were determined by qRT-PCR (A) and western blotting (B), respectively. (C) For SIRT1 activity measurement, 16-HBE cells were incubated indicated concentration of bergenin $(0-200 \mu \mathrm{M})$ for $24 \mathrm{~h}$, and then nuclear extracts was collected and subjected to SIRT1 activity determination using SIRT1 Deacetylase Activity Assay Kit. (D and E) Acetylation level of p53 (D) and p65 (E) in 16-HBE cells with bergenin $(0-200 \mu \mathrm{M})$ incubation for $24 \mathrm{~h}$ were determined by western blotting. GAPDH was used as loading control. (F) Protein band intensities of SIRT1, Acetyl-p53 and Acetyl-P65 in (B, D, E) were measured by ImageJ software. (G-H) mRNA and protein levels of IL- 6 and IL-8 were determined by qPCR and ELISA in the culture supernatant of TNF-X-stimulated $16-\mathrm{HBE}$ cells with single treatment indicated concentration of bergenin or salermide $(10 \mu \mathrm{M})$ and combination treatment for $24 \mathrm{~h}$. Data were presented as means \pm SEM of three independent experiments. $\# \mathrm{P}<0.05 \rrbracket \# \mathrm{P}<0.01 \rrbracket \# \# \# \mathrm{P}<0.001$ compared to untreated cells; $* * * \mathrm{P}<0.001$ compared to TNF-囚treated alone.
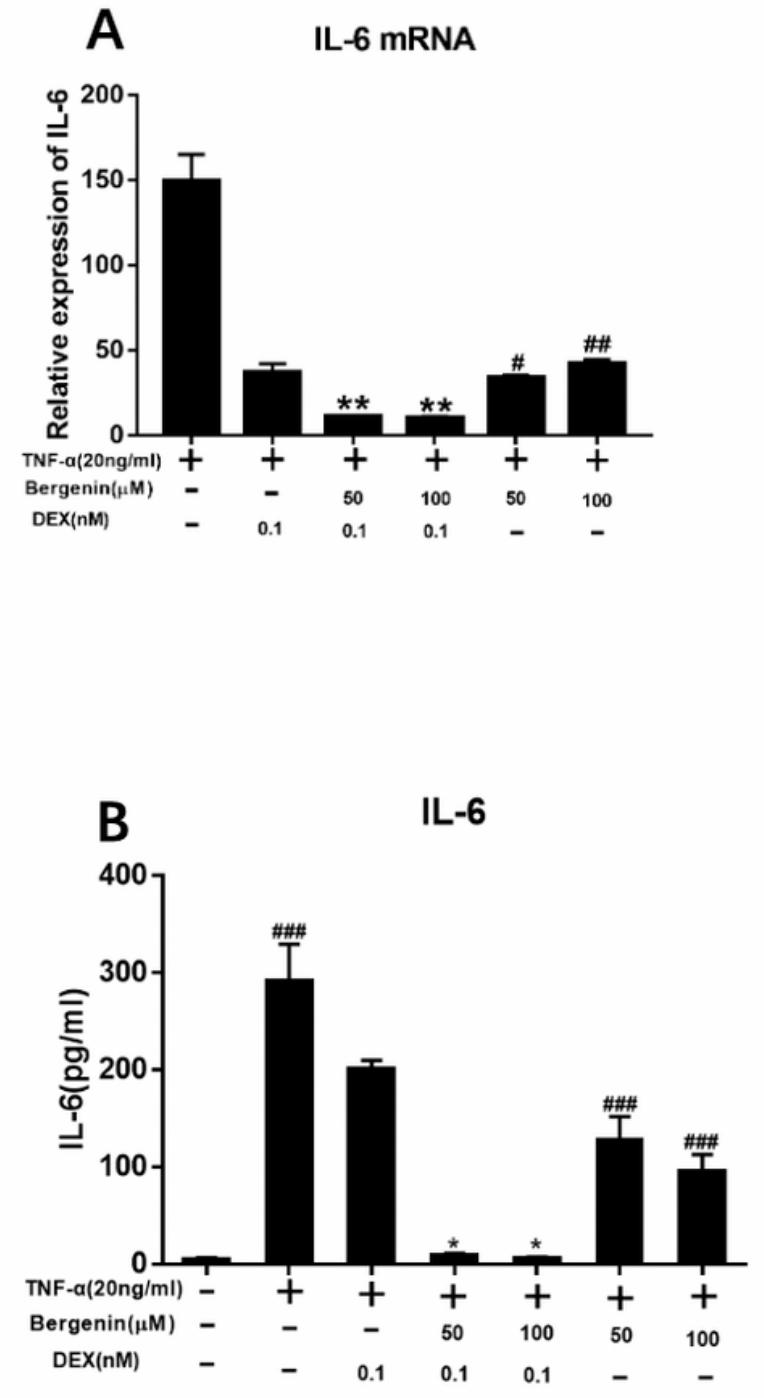

\section{IL-8 mRNA}

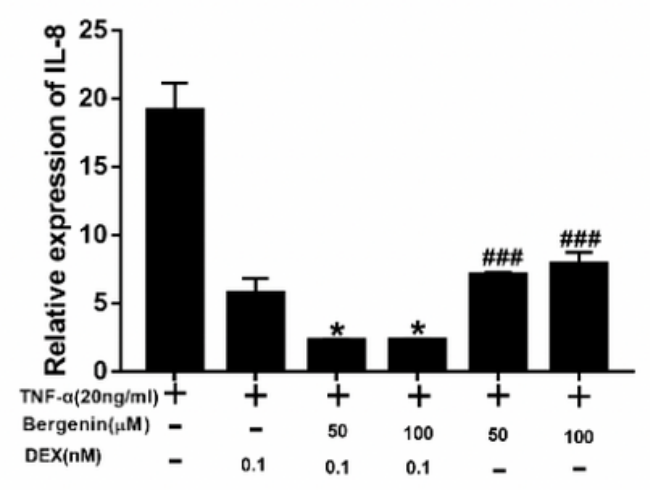

Figure 5 
Effect of dexamethasone and bergenin combination treatment on IL- 6 and IL-8 production in TNF-astimulated 16-HBE cells. (A-B) TNF-囚-stimulated 16-HBE cells were single treated indicated concentration of bergenin or dexamethasone $(0.1 \mathrm{nM})$ and combination treatment for $24 \mathrm{~h}$. mRNA (A) and protein (B) levels of IL- 6 and IL-8 were determined by qRT-PCR and ELISA. \#P $<0.05$, \#\#P $<0.01$, \#\#\#P 0.001 compared to untreated cells; $* \mathrm{P}<0.05, * * \mathrm{P}<0.01$ compared to TNF-X-treated alone. 